\title{
Optimization of Polyurethane Membrane Physical Characteristics of Red Seaweed Biomass Using a Box-Behnken Design
}

\author{
Salfauqi Nurman ${ }^{1,2,3}$, Saiful $^{4}$, Binawati Ginting $^{4}$, Rahmi $^{4}$, and Marlina ${ }^{4}$ \\ ${ }^{1}$ Graduate School of Mathematics and Applied Sciences, Universitas Syiah Kuala, Banda Aceh 23111, Indonesia \\ ${ }^{2}$ Department of Agricultural Industrial Engineering, Faculty of Agricultural Technology, Universitas Serambi Mekkah, \\ Banda Aceh 23245, Indonesia \\ ${ }^{3}$ Malahayati Merchant Marine Polytechnic, Aceh Besar 23381, Indonesia \\ ${ }^{4}$ Department of Chemistry, Faculty of Mathematics and Natural Sciences, Universitas Syiah Kuala, Banda Aceh 23111, Indonesia
}

*Corresponding author:

tel: $+62-81360581225$

email:saiful@unsyiah.ac.id

Received: January 27, 2021

Accepted: April 21, 2021

DOI: $10.22146 /$ ijc. 63649

\begin{abstract}
The polyurethane membrane is used as a separator either by filtration or adsorption, and this process is significantly affected by its strength and physical condition. We synthesized polyurethane membranes using red seaweed with Gracilaria sp as a hydroxyl source. The Box-Behnken Design of the Response Surface Methodology (RSM) using Software Design Expert Version 10.0.3.0 with three factors (TRL, TDI, and Glycerin). The F-value of 0.42 suggests that the membrane is less fit, while the P-value of $75.10 \%$ indicates that the quadratic design model is suitable for data analysis of physical characteristics. The optimal physical characteristics were obtained at a composition of $0.233 \mathrm{~g}$ TRL, $2.675 \mathrm{~g}$ TDI, and $0.254 \mathrm{~g}$ glycerin with a physical point of 6.5 (strong and elastic). Optimal polyurethane membrane has good thermal and mechanical properties at temperatures of $\mathrm{Tg} 58^{\circ} \mathrm{C}, \mathrm{Tm} 322^{\circ} \mathrm{C}$, and $\mathrm{Td} 534^{\circ} \mathrm{C}$, as well as stress and nominal strain values of $69.3 \mathrm{MPa}$ and $5.74 \%$. Polyurethane membrane synthesized from red seaweed has good physical properties. The result of this research is the basis for the development of polyurethane membrane applications from red seaweed.
\end{abstract}

Keywords: physical characteristics; response surface methodology; optimization; polyurethane membranes

\section{- INTRODUCTION}

Membranes are separators used to separate various substances in a gas mixture [1] or liquid [2-3]. This technology continues to develop due to its high selectivity properties [4-5] as well as its ability to be easily synthesized and applied [6-7]. One of the commonly developed membranes is polyurethane [8], which is a type of polymer membrane composed of urethane bonds [9] and formed from the reaction between compounds containing two or more reactive hydroxyl and isocyanate groups [10-12]. Polyurethane membranes can be synthesized using natural materials, such as carrageenan, which has strong and slightly elastic properties with a tensile strength of $340 \mathrm{kgf} / \mathrm{mm}^{2}$, at a $9 \%$ elongation percentage [13]. In this study, we used the Gracilaria $s p$ type of red seaweed as a hydroxy source for the synthesis of polyurethane membranes due to its abundant availability in coastal areas and the presence of hydroxy groups from carrageenan, alginate, and agar [14].

The polyurethane membrane is also applied as a separator either by filtration [15-16] or adsorption $[2,17]$. The strength and physical condition of the membrane significantly affect the success of the separation process, using a large pressure driving force and a concentration gradient during filtration. Therefore, a strong and slightly elastic membrane is required [6] to produce a suitable polyurethane membrane, which is strongly influenced by the composition of the materials used to regulate the formation of hard and soft segments [18-19]. The 
research used the Box-Behnken Design from Response Surface Methodology (RSM) due to its ability to combine factorial and incomplete group designs to obtain optimal composition [20-21]. This design uses a Design Expert Software Version 10.0.3.0 with three factors and three levels.

Furthermore, RSM is also used to model and analyze the effect of the quantitative variable to obtain optimized results. The relationship between these variables can be described in the form of an equation [22-24]. Furthermore, the response used is the polyurethane membrane's physical or visual characteristics, which assign points to the characteristic level. These points were used as response variables and linked with other factors to produce 3D graphs to determine the optimal composition for polyurethane membrane synthesis. The physical characteristics can be used as a qualitative analysis of polyurethane membranes.

\section{- EXPERIMENTAL SECTION}

\section{Materials}

The materials used were 1,4-dioxane as a solvent, glycerin, castor oil as a plasticizer, and toluene diisocyanate (TDI) as a reagent in Pro's quality Analysis (PA) from Merck (Darmstadt, Germany). The sample used was red seaweed (Gracilaria verucosa Greville) from the ponds in Lamnga Village, Mesjid Raya District, Aceh Besar District, Aceh Province. The seaweed used was Seaweed Flour (TRL) with a particle size of $777.3 \mathrm{~nm}$.

\section{Instrumentation}

The equipment used includes glassware, namely measuring cups, beakers, Petri dishes, magnetic stirrers, hotplates, analytical scales, ovens, grinders, and other supporting tools. While the instruments used are FTIR (IR-Prestige-21, Shimadzu), DSC (DSC-60, Shimadzu), TGA (DTG-60, Shimadzu), SEM (JEOL - 6510 LA) and MTS EM tensile test with ASTM D638 Plastics Tension 1229.

\section{Procedure}

\section{Treatment design}

Due to its ability to combine factorial with incomplete blocking design, the Response Surface
Methodology with Box-Behnken Design was used to synthesize polyurethane membrane [20]. This research was carried out with the Software Design Expert Version 10.0.3.0 with three factors (TRL, TDI, and Glycerin) and three levels (low, medium, and high). As shown in Table 1 , the factors and levels used in this study are based on preliminary investigations. In addition, the combined polyurethane membrane synthesis design using BoxBehnken Design is shown in Table 2.

\section{Polyurethane membrane synthesis}

TRL was weighed according to the combination and put in a beaker containing $5 \mathrm{~g}$ of 1,4-dioxane and $0.5 \mathrm{~g}$ of castor oil. The solution was homogenized for $10 \mathrm{~min}$, followed by the addition of TDI and glycerin. The

Table 1. Design levels of polyurethane membrane synthesis by three factors $(\mathrm{x})$

\begin{tabular}{ccccc}
\hline \multirow{2}{*}{ Factor } & Parameter & \multicolumn{3}{c}{ Level } \\
\cline { 3 - 5 } & & Low $(-)$ & Medium $(0)$ & High $(+)$ \\
\hline $\mathrm{x}_{1}$ & TRL $(\mathrm{g})$ & 0.1 & 0.2 & 0.3 \\
$\mathrm{x}_{2}$ & TDI (g) & 2.0 & 2.5 & 3.0 \\
$\mathrm{x}_{3}$ & Glycerin $(\mathrm{g})$ & 0.2 & 0.3 & 0.4 \\
\hline
\end{tabular}

TRL: Seaweed flour

TDI: Toluene diisocyanate

Table 2. Combined polyurethane membrane synthesis design using Box-Behnken Design

\begin{tabular}{cccc}
\hline Run & TRL $(\mathrm{g})$ & TDI $(\mathrm{g})$ & Glycerin $(\mathrm{g})$ \\
\hline 1 & 0.2 & 3.0 & 0.4 \\
2 & 0.2 & 2.5 & 0.3 \\
3 & 0.3 & 2.5 & 0.4 \\
4 & 0.2 & 2.0 & 0.2 \\
5 & 0.2 & 3.0 & 0.2 \\
6 & 0.1 & 2.5 & 0.4 \\
7 & 0.2 & 2.5 & 0.3 \\
8 & 0.1 & 2.0 & 0.3 \\
9 & 0.3 & 2.0 & 0.3 \\
10 & 0.1 & 2.5 & 0.2 \\
11 & 0.3 & 2.5 & 0.2 \\
12 & 0.2 & 2.5 & 0.3 \\
13 & 0.2 & 2.0 & 0.4 \\
14 & 0.3 & 3.0 & 0.3 \\
15 & 0.2 & 2.5 & 0.3 \\
16 & 0.2 & 2.5 & 0.3 \\
17 & 0.1 & 3.0 & 0.3 \\
\hline
\end{tabular}


mixture was then polymerized at $60{ }^{\circ} \mathrm{C}$ for $2 \mathrm{~h}$ while stirring using a magnetic stirrer. The dope solution formed was then molded using a petri dish, then placed in a dustfree room at room temperature for $24 \mathrm{~h}$. After forming the membrane sheet, the membrane was removed from the mold by immersing it in warm distilled water for 1-2 $\mathrm{h}$.

\section{Physical characterization}

The visible physical characterization of polyurethane membranes is shown in Table 3. According to points 6 to 7 of the physical characteristics, the membrane is elastic, not easily torn, or strong. This characterization is an initial qualitative analysis used to determine the optimal composition comprising functional group, thermal, and tensile strength analysis.

\section{Polyurethane membrane characterization}

The optimal polyurethane membrane characterization of functional groups using Fourier Transform Infra-Red (FTIR), samples were made into $\mathrm{KBr}$ pellets (ratio 1:20), the spectrum was recorded in the wavenumber range of $4000-400 \mathrm{~cm}^{-1}$. Thermal analysis using the Differential scanning calorimetry (DSC) and Thermogravimetric Analysis (TGA). The observation was carried out under a nitrogen gas flow with a speed of
$20 \mathrm{~mL} / \mathrm{min}$. The sample with a $10-20 \mathrm{mg}$ weight was heated in an aluminum pan at a temperature of $0-600^{\circ} \mathrm{C}$ with a scanning speed of $20{ }^{\circ} \mathrm{C} / \mathrm{min}$. For Scanning Electron Microscope (SEM) analysis, the sample was placed on an aluminum plate and coated with palladium gold in a vacuum chamber. The sample was analyzed using Det.BSE and SE at a voltage of 10,15 , and $20 \mathrm{kV}$. Mechanical analysis using MTS EM tensile test with ASTM D638 Plastics Tension 1229.

\section{- RESULTS AND DISCUSSION}

\section{Physical Characteristics of Polyurethane Membranes}

Polyurethane membranes are formed by the presence of urethane bonds that occur between two main groups, namely hydroxyl $(-\mathrm{OH})$ and isocyanates (NCO) $[18,25]$, as shown in Fig. 1. The urethane bonds can affect the physical properties of the polyurethane membrane. Points 5 to 8 in Table 3 show that the resulting polyurethane membrane has good physical properties, namely elastic, and does not tear easily. The results of the physical characterization are then entered into the Box-Behnken design, as shown in Table 4.

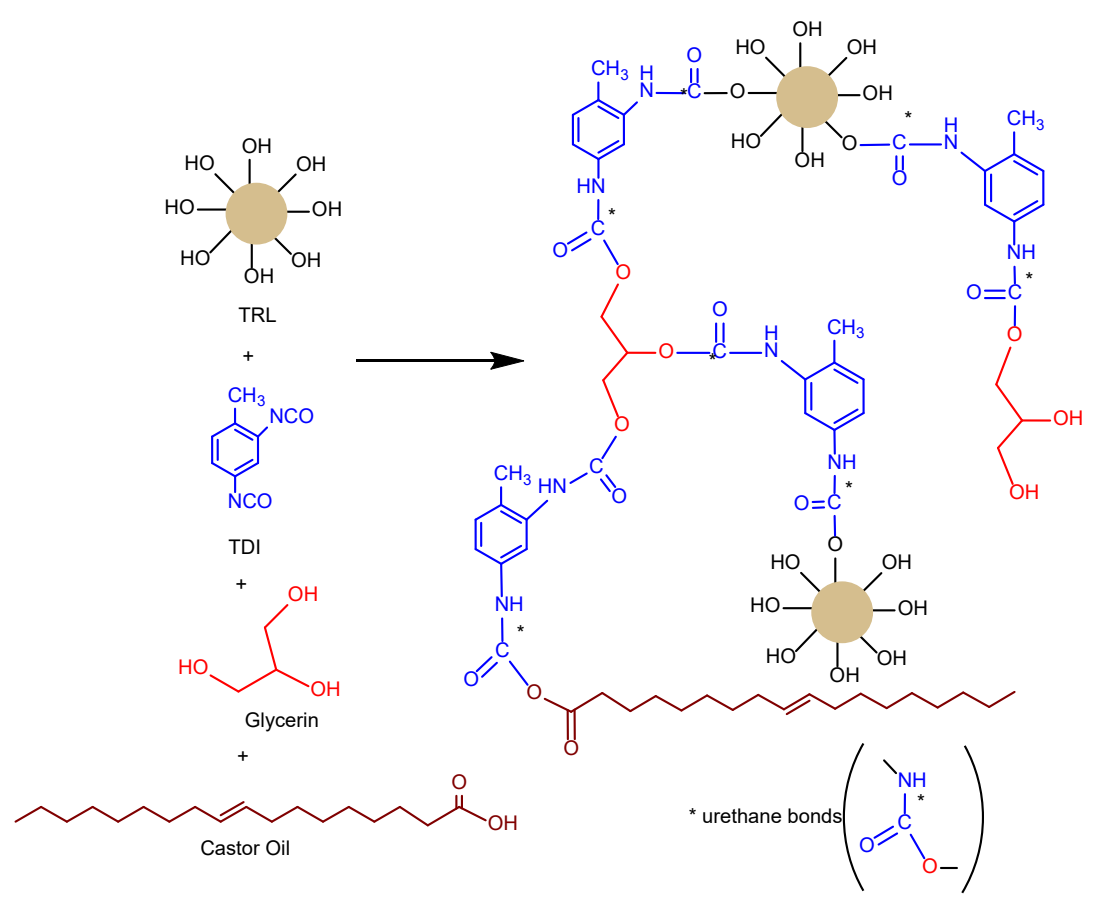

Fig 1. Reaction of polyurethane membrane synthesis 


\section{Statistical Design Model}

The optimum conditions for synthesizing polyurethane membranes were determined using BoxBehnken Design in Software Design Expert Version 10.0.3.0 with three factors $(\mathrm{x})$ in three levels. This led to 17 runs, as shown in Table 2 . The quadratic model design was chosen in this study because it produced high $\mathrm{R}^{2}$ values and low PRESS values for the response to physical characteristics compared to the 2FI, linear, and cubic models. The greater the $\mathrm{R}^{2}$ value, the higher the contribution or role of the factor $(x)$ to the response $(y)$. With the value of $\mathrm{R}^{2}$ above $70 \%$, it is considered to be good enough [20]. Although the cubic model has a high $\mathrm{R}^{2}$ value, it does not have a Pred- $\mathrm{R}^{2}$ and a PRESS value. Therefore, the effect of each variable with a different signal is not controlled. The statistical design and variance analysis of the polyurethane membrane synthesis model are shown in Tables 5 and 6, respectively.

Pred R-Squared and Adj R-Squared values are 0.6694 and 0.8489 , with a reasonable difference of 0.18 , which is less than the expected difference of 0.2. The Adeq Precision value is the signal to noise ratio, which is greater than 4 , with a ratio of 10.520 , in the quadratic model, which indicates an adequate signal. Therefore, this model can be used to navigate spatial design [24,26-27]. The Model F value is 10.99, and Prob > F less than 0.0500 indicates that the model is significant. The significant factors to the polyurethane membrane characteristics are $\mathrm{B}, \mathrm{C}, \mathrm{BC}$, and $\mathrm{B} 2$, with a $\mathrm{p}$-value less than 0.0500 and greater than 0.100 , thereby indicating that the model is insignificant. Furthermore, the insignificance of the Fvalue of lack of fit at 0.42 and a p-value of $75.10 \%$ indicates that the quadratic design model is suitable for

Table 3. Point physical characteristics of polyurethane membranes

\begin{tabular}{clc}
\hline No & Physical characteristics & Point \\
\hline 1 & Crushed or shapeless & 1 \\
2 & Brittle or crumbles easily & 2 \\
3 & Not elastic and breaks easily & 3 \\
4 & Not elastic and does not break easily & 4 \\
5 & Elastic and easy to tear & 5 \\
6 & Elastic does not tear easily & 6 \\
7 & Elastic and strong & 7 \\
8 & Stiff and easy to tear & 8 \\
9 & Stiff and not easily tear & 9 \\
10 & Rigid and hard & 10 \\
\hline
\end{tabular}

Table 4. The physical characteristics results of the polyurethane membrane

\begin{tabular}{ccccc}
\hline Run & $\begin{array}{c}\text { Factor } 1 \\
\text { A:TRL }(\mathrm{g})\end{array}$ & $\begin{array}{c}\text { Factor } 2 \\
\text { B: TDI }(\mathrm{g})\end{array}$ & $\begin{array}{c}\text { Factor } 3 \\
\text { C: Glycerin }(\mathrm{g})\end{array}$ & Response Physical (Point) \\
\hline 1 & 0.2 & 3.0 & 0.4 & 8 \\
2 & 0.2 & 2.5 & 0.3 & 8 \\
3 & 0.3 & 2.5 & 0.4 & 5 \\
4 & 0.2 & 2.0 & 0.2 & 5 \\
5 & 0.2 & 3.0 & 0.2 & 7 \\
6 & 0.1 & 2.5 & 0.4 & 7 \\
7 & 0.2 & 2.5 & 0.3 & 5 \\
8 & 0.1 & 2.0 & 0.3 & 5 \\
9 & 0.3 & 2.0 & 0.3 & 6 \\
10 & 0.1 & 2.5 & 0.2 & 7 \\
11 & 0.3 & 2.5 & 0.2 & 6 \\
12 & 0.2 & 2.5 & 0.3 & 7 \\
13 & 0.2 & 2.0 & 0.4 & 6 \\
14 & 0.3 & 3.0 & 0.3 & 7 \\
15 & 0.2 & 2.5 & 0.3 & 6 \\
16 & 0.2 & 2.5 & 0.3 & 6.3 \\
17 & 0.1 & 3.0 & 0.3 & \\
\hline
\end{tabular}


Table 5. Statistical design model of polyurethane membrane synthesis

\begin{tabular}{llccl}
\hline Source & Linear & 2FI & Quadratic & Cubic \\
\hline Std.Dev & 0.69 & 0.68 & 0.39 & 0.45 \\
R-Square & 0.6139 & 0.7083 & 0.9339 & 0.9496 \\
Adj R-Square & 0.5248 & 0.5333 & 0.8489 & 0.7985 \\
Pred R-Square & 0.3010 & -0.0444 & 0.6694 & N/A \\
Adeq Precision & 9.005 & 6.869 & 10.520 & 7.671 \\
PRESS & 11.10 & 16.59 & 5.25 & N/A \\
\hline
\end{tabular}

Table 6. ANOVA analysis for a quadratic model of the physical characteristics of a polyurethane membrane

\begin{tabular}{lcrcrcr}
\hline Source & Sum of Squares & $\mathrm{df}$ & Mean Square & F Value & p-value Prob $>$ F & Characterization \\
\hline Model & 14.83 & 9 & 1.65 & 10.99 & 0.0023 & significant \\
A-TRL & 0.50 & 1 & 0.50 & 3.33 & 0.1106 & \\
B-TDI & 3.13 & 1 & 3.13 & 20.83 & 0.0026 & \\
C-Glycerin & 6.13 & 1 & 6.13 & 40.83 & 0.0004 & \\
AB & 0.25 & 1 & 0.25 & 1.67 & 0.2377 & 0.2377 \\
AC & 0.25 & 1 & 0.25 & 1.67 & 0.0364 & not significant \\
BC & 1.00 & 1 & 1.00 & 6.67 & 0.4529 & \\
$\mathrm{~A}^{2}$ & 0.095 & 1 & 0.095 & 0.63 & 0.0020 & \\
$\mathrm{~B}^{2}$ & 3.41 & 1 & 3.41 & 22.74 & \\
$\mathrm{C}^{2}$ & 0.042 & 1 & 0.042 & 0.28 & 0.6126 & \\
Residual & 1.05 & 7 & 0.15 & & & \\
Lack of Fit & 0.25 & 3 & 0.083 & 0.42 & & \\
Pure Error & 0.80 & 4 & 0.20 & & & \\
Cor Total & 15.88 & 16 & & & & \\
\hline
\end{tabular}

data analysis of physical characteristics [28]. The relationship between the polyurethane membrane's physical characteristics and the factor $(\mathrm{x})$ based on the coefficient value is seen in Eq. (1) and the 3D plot in Fig. 2. $\mathrm{y}=6.80+0.25(\mathrm{~A})+0.63(\mathrm{~B})+0.88(\mathrm{C})+0.25(\mathrm{AB})+0.25(\mathrm{AC})$ $+0.50(\mathrm{BC})-0.15(\mathrm{~A})^{2}-0.90(\mathrm{~B})^{2}+0.100(\mathrm{C})^{2}$

\section{Polyurethane Membrane Optimization}

The optimization results using the Response Surface Methodology with Box-Behnken Design provide five solutions of polyurethane membrane composition from seaweed flour, as shown in Table 7. These five solutions can be used as a reference for the production of polyurethane membranes because they have a Desirability value of 1.0 [29]. The optimization results using the Response Surface Methodology resulted in a predictive physical value of 6.5 with strong and elastic physical characteristics. The experimental results of the optimal composition show the physical values 6 and 7 , the results of the predictions and experiments show the appropriate results.

\section{Optimal Polyurethane \\ Characterization}

The FTIR spectrum results in Fig. 3 show the formation of the urethane bonds on the polyurethane membrane, indicated by the absorption attributable to the $-\mathrm{NH}$ bond at the wavenumber of 1583 and $3348 \mathrm{~cm}^{-1}$. It is also supported by the vibration of the $-\mathrm{C}=\mathrm{O}$ bond at the wavenumber of $1726 \mathrm{~cm}^{-1}$ with an intensity of $63.56 \%,-\mathrm{CN}$ amine at the wavenumber of $1249 \mathrm{~cm}^{-1}$ with an intensity of $63.38 \%$, as well as $-\mathrm{CH}$ alkane the wavenumber $2931 \mathrm{~cm}^{-1}$ with an intensity of $66.29 \%$. In addition, the weakening of the - NCO uptake of toluene diisocyanate was also observed at the wavenumber $2265 \mathrm{~cm}^{-1}$ [30].

Thermal analysis is an important parameter used to determine the membrane's stability against temperature 
(a)

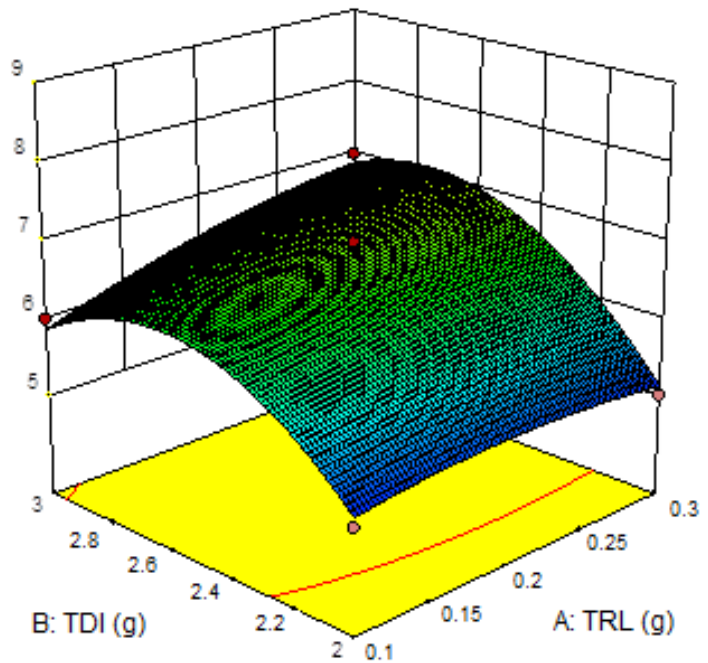

(b)

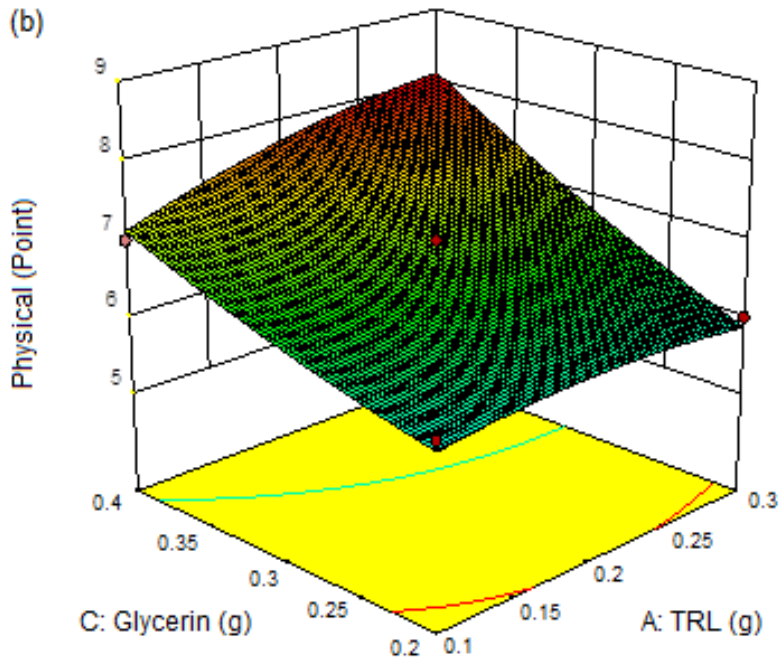

(c)

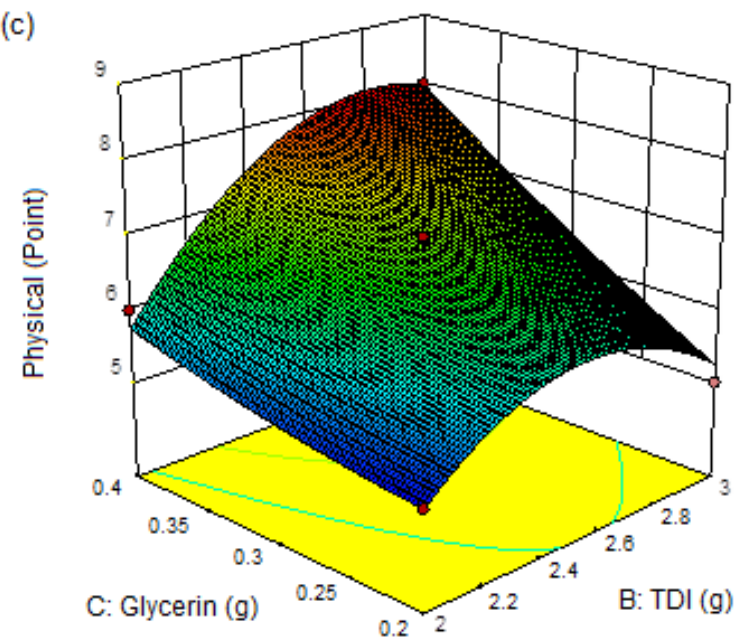

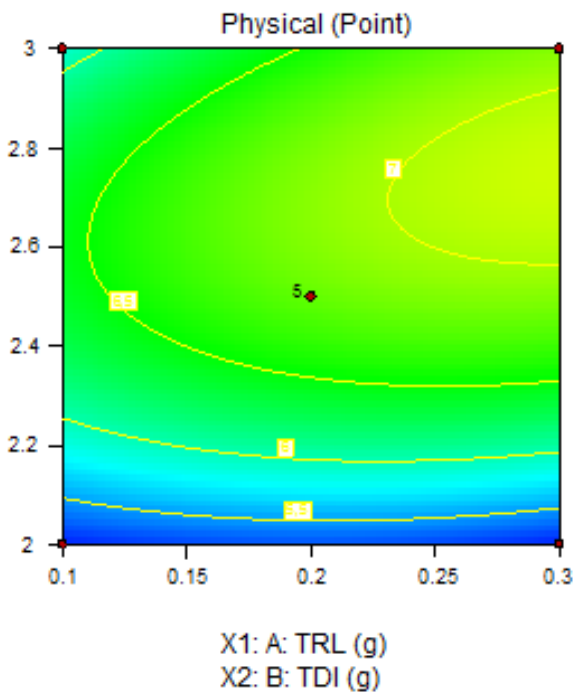
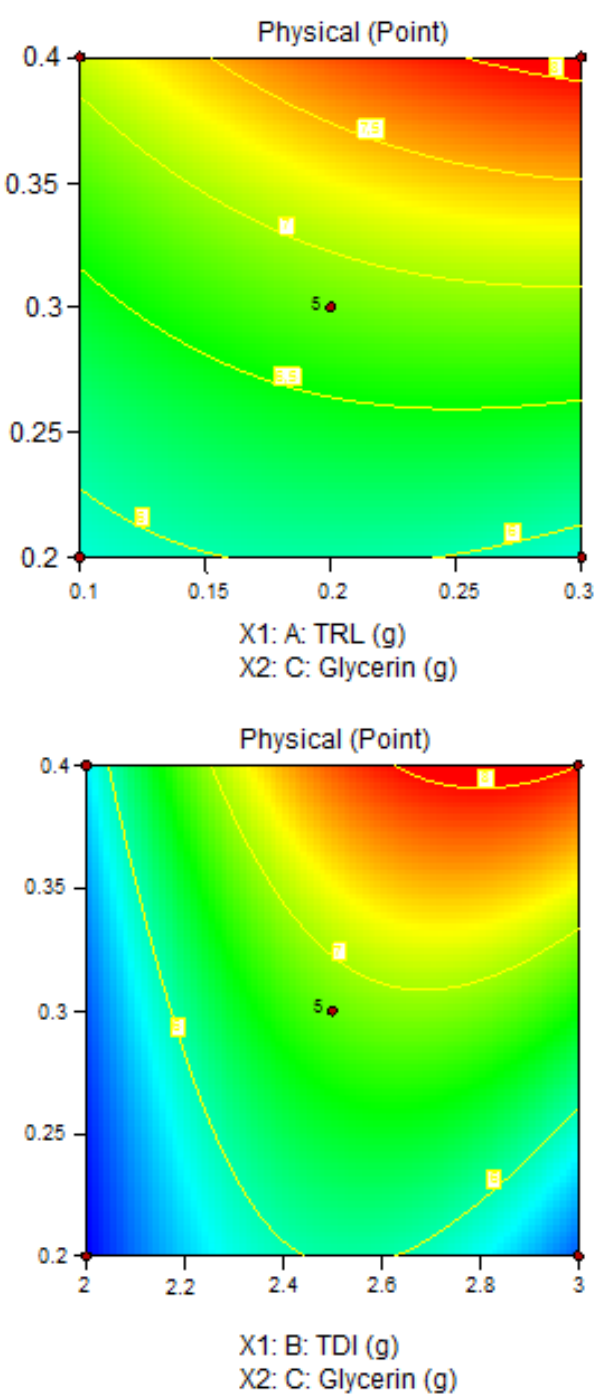

Fig 2. 3D plot and surface plot of the relationship between (a) TRL and TDI to Physical, (b) TRL and Glycerin to Physical (c) TDI and Glycerin to Physical 
Table 7. Optimal compositional solution for polyurethane membrane synthesis

\begin{tabular}{ccccccc}
\hline No & TRL (g) & TDI (g) & Glycerin (g) & $\begin{array}{c}\text { Physical (point) } \\
\text { Predictions }\end{array}$ & $\begin{array}{c}\text { Physical (point) } \\
\text { Experiment }\end{array}$ & Desirability \\
\hline 1 & 0.233 & 2.675 & 0.254 & 6.5 & 7 & 1.0 \\
2 & 0.218 & 2.546 & 0.257 & 6.5 & 6 & 1.0 \\
3 & 0.136 & 2.849 & 0.304 & 6.5 & - & 1.0 \\
4 & 0.281 & 2.197 & 0.352 & 6.5 & - & 1.0 \\
5 & 0.192 & 2.156 & 0.394 & 6.5 & - & 1.0 \\
\hline
\end{tabular}

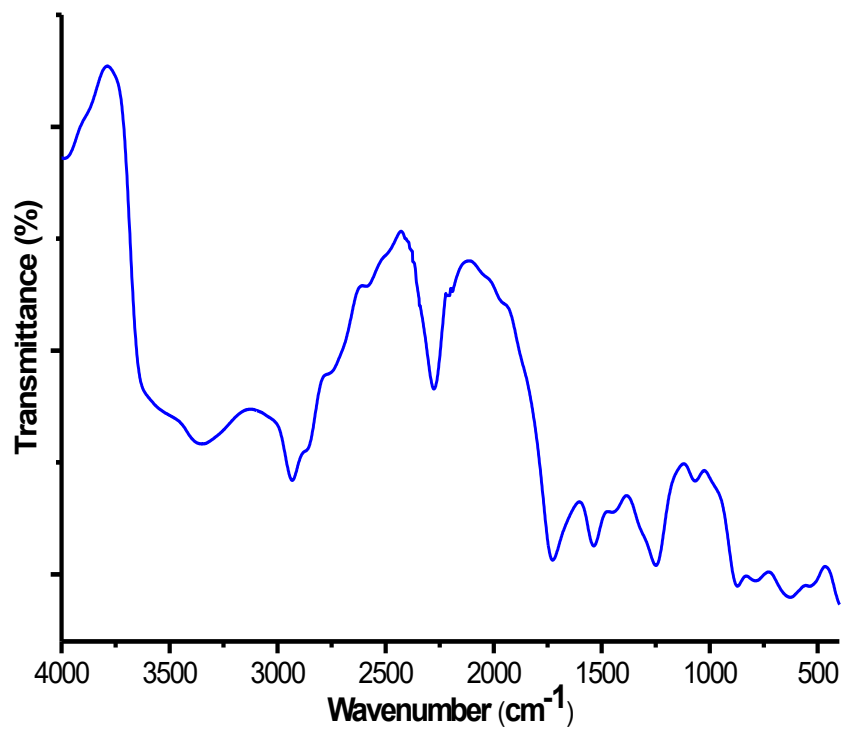

Fig 3. Optimal FTIR spectrum of polyurethane membranes

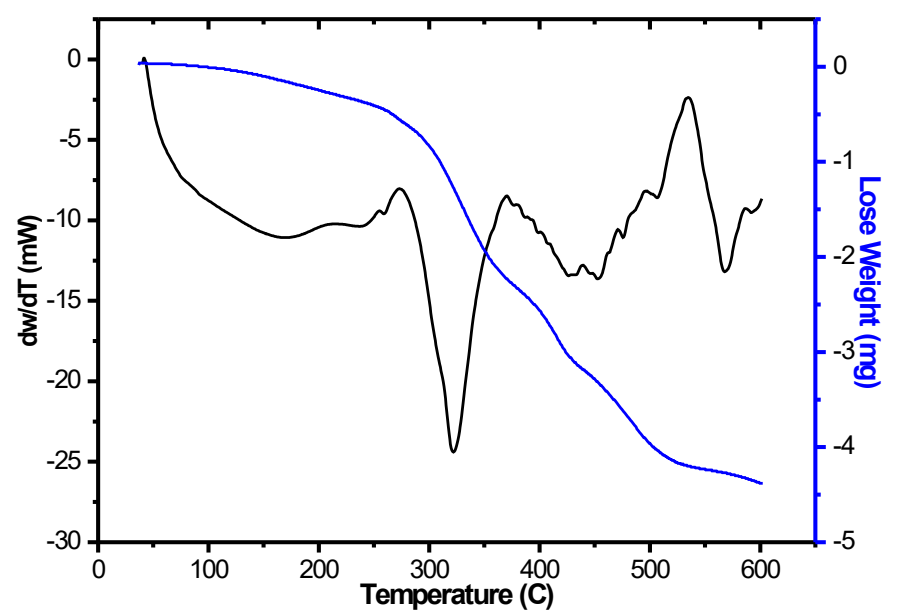

Fig 4. Optimal DSC thermogram and TGA polyurethane membrane

during storage and usage. The DSC thermogram (Fig. 4) shows that the optimal polyurethane membrane has a $\mathrm{T}_{\mathrm{g}}$ of $58{ }^{\circ} \mathrm{C}, \mathrm{T}_{\mathrm{m}}$ of $322{ }^{\circ} \mathrm{C}$, and $\mathrm{T}_{\mathrm{d}}$ of $534{ }^{\circ} \mathrm{C}$, while the polyurethane membranes have $\mathrm{T}_{\mathrm{m}}$ and $\mathrm{T}_{\mathrm{d}}$ values. This high level is caused by the strong urethane bonds and cross-links that form crystal segments or regularities in the hard segments $[1,18]$. The polyurethane membrane from carrageenan has a $\mathrm{T}_{\mathrm{g}}$ of $243^{\circ} \mathrm{C}$ and $\mathrm{T}_{\mathrm{m}}$ of $423{ }^{\circ} \mathrm{C}$. The difference in value is due to the difference in the base material used and the polymerization conditions [13]. The TGA thermogram shows the change in sample weight to the optimal temperature rise of the polyurethane membrane at an initial degradation temperature ranging from 105.24 to $267.48^{\circ} \mathrm{C}$ for water evaporation and cellulose determination. The weakest units in the macromolecular structure of the next degradation temperature are in the range of 267.48$423.17^{\circ} \mathrm{C}$, which is the degradation of urea and urethane bonds from hard segments and other aliphatic bonds. The final degradation value above $423.17{ }^{\circ} \mathrm{C}$ is the remaining structures [25,31-33] with a residue of $11.7 \%$.

The SEM results of the optimal polyurethane membrane can be seen in Fig. 5. There is a gap on the inside of the membrane formed from the urethane bonds. The polyurethane membrane produced in this study is

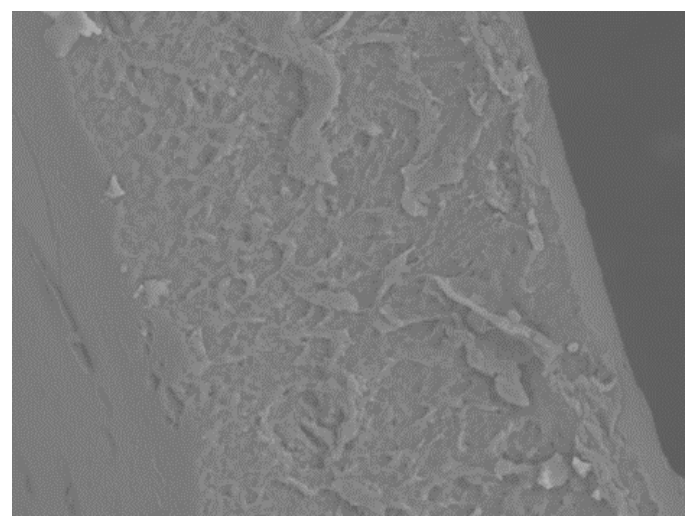

Fig 5. Cross-section of optimal polyurethane membrane 


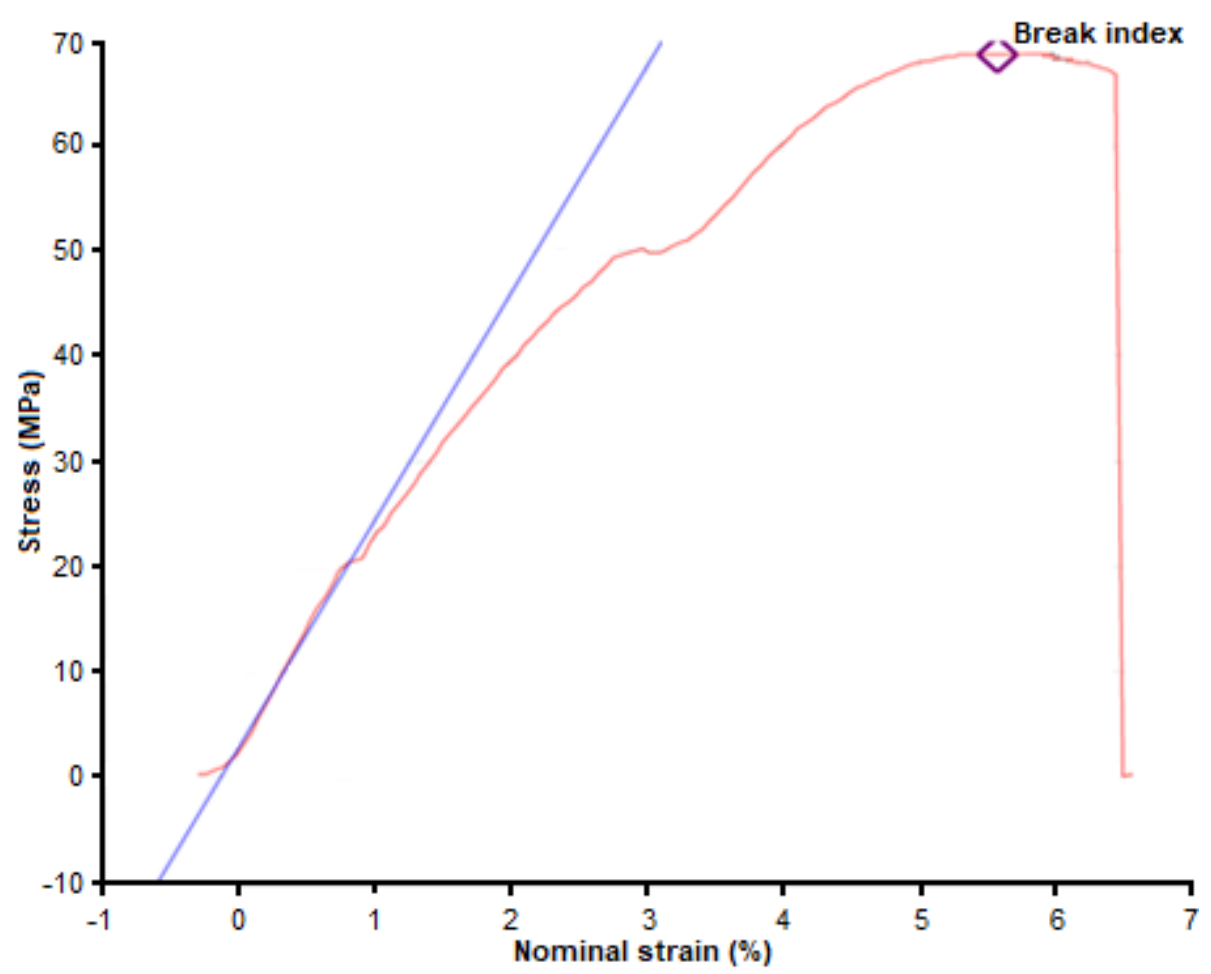

Fig 6. Optimal polyurethane membrane tensile strength curve

applied to the ammonia adsorption and filtration processes. In future studies, it needs to have good mechanical properties with the ability to withstand water pressure. The optimal polyurethane membrane's mechanical properties are good, with a stress value of 69.3 MPa and a nominal strain of 5.74\%, as shown in Fig. 6. The expected polyurethane membrane has strong mechanical properties, and it is slightly elastic, with the strength of the membrane related to its ability to withstand water pressure. Meanwhile, the elongation or the level of membrane elasticity is related to the strain of pore size, which can affect the adsorption or filtration process of the analyte.

\section{- CONCLUSION}

The polyurethane membrane's optimal physical characteristics made from red seaweed were obtained at a composition of $0.233 \mathrm{~g}$ TRL, $2.675 \mathrm{~g}$ TDI, and $0.254 \mathrm{~g}$ glycerin with a physical point of 6.5 (strong and elastic). Optimal polyurethane membrane has good thermal and mechanical properties, with a value of $\mathrm{T}_{\mathrm{g}}$ of $58{ }^{\circ} \mathrm{C}, \mathrm{T}_{\mathrm{m}}$ of $322{ }^{\circ} \mathrm{C}, \mathrm{T}_{\mathrm{d}}$ of $534{ }^{\circ} \mathrm{C}$, a stress value of $69.3 \mathrm{MPa}$, and a nominal strain of $5.74 \%$. The polyurethane membrane synthesized from red seaweed has good physical characteristics. The results of this study are the basis for the development of polyurethane membrane applications from red seaweed.

\section{- ACKNOWLEDGMENTS}

The authors are grateful to the Universitas Syiah Kuala and Universitas Serambi Mekkah for supporting and facilitating this research.

\section{- AUTHOR CONTRIBUTIONS}

SN conducted the experiment, S, BG, R, and $M$ supervised and revised the manuscript. All authors agreed to the final version of this manuscript.

\section{- REFERENCES}

[1] Karimi, M.B., Khanbabaei, G., Mir, G., and Sadeghi, G.M.M., 2017, Vegetable oil-based polyurethane membrane for gas separation, J. Membr. Sci., 527, 198-206.

[2] Hao, S., Jia, Z., Wen, J., Li, S., Peng, W., Huang, R., and $\mathrm{Xu}, \mathrm{X} ., 2021$, Progress in adsorptive membranes for separation - A review, Sep. Purif. Technol., 255, 
117772.

[3] Kyllönen, H.M., Pirkonen, P., and Nyström, M., 2005, Membrane filtration enhanced by ultrasound: A review, Desalination, 181 (1-3), 319-335.

[4] Zhao, D.L., Japip, S., Zhang, Y., Weber, M., Maletzko, C., and Chung, T.S., 2020, Emerging thin-film nanocomposite (TFN) membranes for reverse osmosis: A review, Water Res., 173, 115557.

[5] Joshi, M., Adak, B., and Butola, B.S., 2018, Polyurethane nanocomposite based gas barrier films, membranes and coatings: A review on synthesis, characterization and potential applications, Prog. Mater Sci., 97, 230-282.

[6] Ersahin, M.E., Ozgun, H., Dereli, R.K., Ozturk, I., Roest, K., and van Lier, J.B., 2012, A review on dynamic membrane filtration: Materials, applications and future perspectives, Bioresour. Technol., 122, 196-206.

[7] Singh, I., and Mishra, P.K., 2020, Nano-membrane filtration a novel application of nanotechnology for waste water treatment, Mater. Today: Proc., 29, 327332.

[8] Marlina, Iqhrammullah, M., Saleha, S., Fathurrahmi, Maulina, F.P., and Idroes, R., 2020, Polyurethane film prepared from ball-milled algal polyol particle and activated carbon filler for $\mathrm{NH}_{3}-\mathrm{N}$ removal, Heliyon, 6 (8), e04590.

[9] Howard, G.T., 2002, Biodegradation of polyurethane: A review, Int. Biodeterior. Biodegrad., 49 (4), 245-252.

[10] Nurman, S., Marlina, Saiful, and Saleha, S., 2015, Sintesis dan karakterisasi membran poliuretan dari minyak biji karet dan heksametilen-1,6-diisosianat, JRKL, 10 (4), 188-195.

[11] Matavos-Aramyan, S., Jazebizadeh, M.H., and Babaei, S., 2020, Investigating $\mathrm{CO}_{2}, \mathrm{O}_{2}$ and $\mathrm{N}_{2}$ permeation properties of two new types of nanocomposite membranes: Polyurethane/silica and polyesterurethane/silica, Nano-Struct. Nano-Objects, 21, 100414.

[12] Zhang, X.D., Macosko, C.W., and Davis, H.T., 1997, Effect of silicone surfactant on air flow of flexible polyurethane foams, ACS Symp. Ser., 669, 130-142.
[13] Marlina, 2010, Sintesis membran poliuretan dari karagenan dan 2,4 toylulene diisosianat, $J R K L, 7$ (3) 138-148.

[14] Sedayu, B.B., Cran, M.J., and Bigger, S.W., 2019, A review of property enhancement techniques for carrageenan-based films and coatings, Carbohydr. Polym., 216, 287-302.

[15] Hube, S., Eskafi, M., Hrafnkelsdóttir, K.F., Bjarnadóttir, B., Bjarnadóttir, M.A., Axelsdóttir, S., and $\mathrm{Wu}, \mathrm{B} ., 2020$, Direct membrane filtration for wastewater treatment and resource recovery: A review, Sci. Total Environ., 710, 136375.

[16] Hoslett, J., Massara, T.M., Malamis, S., Ahmad, D., van den Boogaert, I., Katsou, E., Ahmad, B., Ghazal, H., Simons, S., Wrobel, L., and Jouhara, H., 2018, Surface water filtration using granular media and membranes: A review, Sci. Total Environ., 639, 1268-1282.

[17] Dlamini, D.S., Tesha, J.M., Vilakati, G.D., Mamba, B.B., Mishra, A.K., Thwala, J.M., and Li, J., 2020, A critical review of selected membrane- and powderbased adsorbents for water treatment: Sustainability and effectiveness, J. Cleaner Prod., 277, 123497.

[18] Li, R., and Shan, Z., 2020, Study on structureinduced heat transfer capabilities of waterborne polyurethane membranes, Colloids Surf., A, 598, 124879.

[19] Melnig, V., Apostu, M.O., Tura, V., and Ciobanu, C., 2005, Optimization of polyurethane membranes: Morphology and structure studies, J. Membr. Sci., 267, 58-67.

[20] Tekindal, M.A., Bayrak, H., Ozkaya, B., and Genc, Y., 2012, Box-Behnken experimental design in factorial experiments: The importance of bread for nutrition and health, Turk. J. Field Crops, 17 (2), 115-123.

[21] Khajeh, M., and Gharan, M., 2014, Separation of organic acid compounds from biological samples by zinc oxide nanoparticles-chitosan using genetic algorithm based on response surface methodology and artificial neural network, J. Chemom., 28 (7), 539-547. 
[22] Myers, R.H., Montgomery, D.C., and AndersonCook, C.M., 2002, Response Surface Methodology: Process and Product Optimization Using Designed Experiments, $2^{\text {nd }}$ Ed., John Wiley \& Sons, Inc., New York, USA.

[23] Khajeh, M., Kaykhaii, M., and Sharafi, A., 2013, Application of PSO-artificial neural network and response surface methodology for removal of methylene blue using silver nanoparticles from water samples, J. Ind. Eng. Chem., 19 (5), 1624-1630.

[24] Khajeh, M., Moghaddam, M.G., Danesh, A.Z., and Khajeh, B., 2015, Response surface modeling of betulinic acid pre-concentration from medicinal plant samples by miniaturized homogenous liquidliquid extraction and its determination by high performance liquid chromatography, Arabian $J$. Chem., 8 (3), 400-406.

[25] Das, B., Konwar, U., Mandal, M., and Karak, N., 2013, Sunflower oil based biodegradable hyperbranched polyurethane as a thin film material, Ind. Crops Prod., 44, 396-404.

[26] Chelladurai, S.J.S., Murugan, K., Ray, A.P., Upadhyaya, M., Narasimharaj, V., and Gnanasekaran, S., 2021, Optimization of process parameters using response surface methodology: A review, Mater. Today: Proc., 37 (2), 1310-1304.

[27] Khajeh, M., Sarafraz-Yazdi, A., and Moghadam, A.F., 2017, Modeling of solid-phase tea waste extraction for the removal of manganese and cobalt from water samples by using PSO-artificial neural network and response surface methodology, Arabian J. Chem., 10 (Suppl. 2), S1663-S1673.
[28] Mäkelä, M., 2017, Experimental design and response surface methodology in energy applications: A tutorial review, Energy Convers. Manage., 151, 630-640.

[29] Zhao, Z., Cuéllar-Bermúdez, S., Ilyas, A., Muylaert, K., and Vankelecom, I.F.J., 2020, Optimization of negatively charged polysulfone membranes for concentration and purification of extracellular polysaccharides from Arthrospira platensis using the response surface methodology, Sep. Purif. Technol., 252, 117385.

[30] Zhang, F., Liu, W., Liang, L., Liu, C., Wang, S., Shi, H., Xie, Y., Yang, M., and Pi, K., 2020, Applications of hydrophobic $\alpha, \omega$-bis(amino)-terminated polydimethylsiloxane-graphene oxide in enhancement of anti-corrosion ability of waterborne polyurethane, Colloids Surf., A, 600, 124981.

[31] Marlina, Saiful, Saleha, S., and Nurman, S., 2017, 2017, Synthesis and characterization new polyurethane membrane from hydroxylated rubber seed oil, Orient. J. Chem., 33 (1), 199-206.

[32] Ghadimi, A., Gharibi, R., Yeganeh, H., and Sadatnia, B., 2019, Ionic liquid tethered PEG-based polyurethane-siloxane membranes for efficient $\mathrm{CO}_{2} / \mathrm{CH}_{4}$ separation, Mater. Sci. Eng. C, 102, 524535.

[33] Wu, J., Wang, C., Xiao, Y., Mu, C., and Lin, W., 2020, Fabrication of water-resistance and durable antimicrobial adhesion polyurethane coating containing weakly amphiphilic poly(isobornyl acrylate) side chains, Prog. Org. Coat., 147, 105812. 